\title{
Vitamin D Supplementation for Pregnant Women in Bulgaria
}

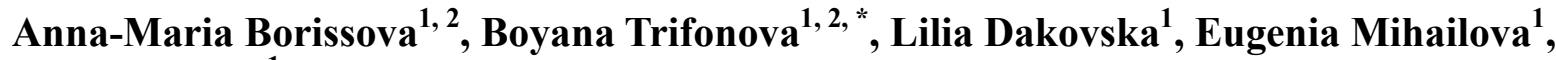 \\ Mircho Vukov ${ }^{1}$
}

${ }^{1}$ Clinic of Endocrinology, University Hospital Sofiamed, Sofia, Bulgaria

${ }^{2}$ Medical Faculty, Sofia University Saint Kliment Ohridski, Sofia, Bulgaria

\author{
Email address: \\ boianatri@abv.bg (B. Trifonova) \\ ${ }^{*}$ Corresponding author
}

\section{To cite this article:}

Anna-Maria Borissova, Boyana Trifonova, Lilia Dakovska, Eugenia Mihailova, Mircho Vukov. Vitamin D Supplementation for Pregnant Women in Bulgaria. European Journal of Preventive Medicine. Vol. 8, No. 4, 2020, pp. 56-60. doi: 10.11648/j.ejpm.20200804.14

Received: June 30, 2020; Accepted: July 22, 2020; Published: August 18, 2020

\begin{abstract}
The aim: of our study was to evaluate the levels of 25-hydroxy vitamin D [25 (OH) D] in pregnant Bulgarian women with and without vitamin D supplementation. Material and methods: We investigated 547 pregnant Bulgarian women, mean age $30 \pm 5$ years, median 30 (18-47). All pregnant women filled in a specially designed standard questionnaire. The cohort consisted of 547 unselected pregnant women, $278 / 547(50.82 \%)$ taking vitamins at the time of the investigation, as a monotherapy or in combination with other medications. We introduced four category level of vitamin D: Severe deficiency: $<10$ ng / ml; Moderate deficiency: 10 - $20 \mathrm{ng} / \mathrm{ml}$; Insufficiency: 20 - $30 \mathrm{ng} / \mathrm{ml}$; Sufficiency: > $30 \mathrm{ng} / \mathrm{ml}$. The peripheral levels of 25(OH)D were investigated using a standard Electro Chemyluminescence Immuno Assay (Competition principle) in a central laboratory on the day of the sampling. Results: For the whole group (547 pregnant women), the mean 25(OH)D level was $25.86 \pm 9.46 \mathrm{ng} / \mathrm{ml}$; median 24.51 (7.96 - 70.00), corresponding to mild insufficiency. Sufficient vitamin D ( $\geq 30 \mathrm{ng} / \mathrm{ml}) \mathrm{had}$ a significantly higher percentage of pregnant women supplemented with vitamin D compared to the non-supplemented group - 87 $(31.29 \%)$ versus $61(22.68 \%), \mathrm{P}<0.05$. At the same time, vitamin D deficiency $(<20 \mathrm{ng} / \mathrm{ml})$ was significantly higher in pregnant women without supplementation with vitamin D - 86 (31.98\%) versus those with supplementation - $61(21.94 \%)$, P $<0.01$. In conclusion: the levels of vitamin D among pregnant Bulgarian women are within the span of mild insufficiency, probably due to the intake of combined vitamin supplements by approximately half of the studied women during the pregnancy.
\end{abstract}

Keywords: Vitamin D, Pregnancy, Vitamin Supplementation

\section{Introduction}

Vitamin D deficiency (VDD) is a global health care issue, with billions carrying deficiency or insufficiency around the world. This hormone plays an important role throughout pregnancy, so that maintenance of an adequate vitamin D status is essential in this setting. Several studies, which have investigated vitamin D status in different populations of pregnant women, have reported high prevalence of vitamin D insufficiency, consistently higher than $50 \%$ [1]. A systematic review has shown that $25(\mathrm{OH}) \mathrm{D}$ concentrations below 50 and $25 \mathrm{nmol} / \mathrm{L}$ during pregnancy were reported in $64 \%$ and $9 \%$ of Americans, and $57 \%$ and $23 \%$ of Europeans [2]. Reasons for vitamin $\mathrm{D}$ deficiency, which have been widely reported among pregnant women, are connected with low sun exposure, high BMI, low vitamin D intakes and some socioeconomic disadvantages such as poor quality diets. These women are at greatest risk of vitamin D deficiency, leading to very low serum concentrations of 25-hydroxyvitamin D [25(OH)D] in their offspring and an increased risk of nutritional rickets. The low vitamin D status in pregnancy may also contribute to the risk of adverse perinatal outcomes including hypertensive disorders (e.g., preeclampsia), fetal growth restriction and preterm birth [3]. Metabolism of 25(OH)D3 was demonstrated in many other organs including the reproductive tract. $25(\mathrm{OH}) \mathrm{D} 3$ and VDR are present in a variety of female reproductive organs such as pituitary glands, hypothalamus, uterus, ovaries, mammary glands, and the placenta [4]. In this line, a-hydroxylase expressed in the decidua and placenta highlights the role of vitamin D synthesis in the 
foetus-maternal interface [5]. Altogether, vitamin D supports placental development and function by regulating placental calcium transport, and by exerting immunomodulatory effects, critical for pregnancy maintenance [6]. Some countries fortify foods products with vitamin D (milk, margarine, vegetable oils and ready-to-eat breakfast cereals), but in Bulgaria this is not implemented. Vitamin D is also included in a multiple micronutrient supplement formulation developed by WHO, the United Nations Children's Fund (UNICEF), for use by pregnant and lactating women [7]. Vitamin D supplementation during pregnancy improves maternal and infant $25(\mathrm{OH}) \mathrm{D}$ concentrations and may play a role in maternal insulin resistance and fetal growth and can also affect peak bone mass, fracture risk, and risk of osteoporosis later in life [8, 9].

There is no data concerning the levels of vitamin $\mathrm{D}$ in pregnant women in Bulgaria. There is also no data on vitamin D supplementation to them. These questions represent an important social issue. We support vitamin D supplementation in pregnancy, having in mind that vitamin D passes through the haemato-placental barrier and aids bone formation of the fetus. The recommendations of the World Health Organization suggest initiation of vitamin D supplementation from 12-16 weeks of gestation until birth [7].

The aim of the study was to clarify the role of vitamin D supplementation for maintaining the optimal level of $25(\mathrm{OH})$ $\mathrm{D}$ in Bulgarian pregnant women, needed for their fetus.

Study design

We undertook a multicenter cross-sectional population-based study performed between September 25 and November 62019 in 10 Bulgarian cities $\left(41^{\circ}-44^{\circ} \mathrm{N}\right)$ and their adjacent villages (overall 84 settlements). We established communication with 104 specialists in Endocrinology, Obstetrics and Gynecology, who invited more than 630 pregnant women to participate in the study and 547 pregnant women consented $(86.83 \%)$.

\section{Materials and Methods}

\subsection{Materials}

We investigated 547 pregnant women, mean age $30 \pm 5$ years, median 30 years (18 - 47 years) - 40\% (28 - 32 y), $23.4 \%$ (33 - 37 y), 21\% (23 - 27 y), 8.4\% (38 - 42 y), 6\% (18 - 22 y) and $1.1 \%$ (43 - 47 y). Prior to the study, written informed consent was obtained from all participants. The conduction of the study was approved by the local Ethics committee at the University Hospital Sofiamed, Sofia, Bulgaria and the study was performed in compliance with the ethical standards laid down in the 1964 Declaration of Helsinki and its later amendments [10]. The investigated pregnant women were a random cohort, without pre-selection. Overall 278/547 (50.82\%) were taking vitamins at the time of the investigation, as a monotherapy or in combination with other medications. All participants were Caucasians and none had liver or kidney diseases or malabsorption. The study did not require a sun exposure diary. During the previous months all pregnant women adhered to their usual daily routine.

\subsection{Choosing the Cut-off for Normal Vitamin D in Pregnant Women}

The levels of $25(\mathrm{OH}) \mathrm{D}$ below $10 \mathrm{ng} / \mathrm{ml}(25 \mathrm{nmol} / \mathrm{l})$ were referred to as severe deficit, $10-20 \mathrm{ng} / \mathrm{ml}(25-50 \mathrm{nmol} / \mathrm{l})$ - a deficit similar to the criteria adopted at the Conference on this topic in Eibsee, Germany in 2012 [11]. Whereas, the Institute of Medicine (IOM) recommendations define sufficiency as vitamin levels above $50 \mathrm{nmol} / \mathrm{L}$ (20 ng / ml), the Endocrine Society clinical practice guideline suggest levels above 75 $\mathrm{nmol} / \mathrm{L}(30 \mathrm{ng} / \mathrm{ml}$ ), and both recommendations are in agreement with other expert opinions in the field that the optimum levels of vitamin D should be 75-125 nmol / L ( $\geq 30$ $\mathrm{ng} / \mathrm{ml}$ ) in order to preserve bone health [12-14]. The latter is crucial during pregnancy for the formation of the fetal skeleton. Keeping in mind above data for pregnant women we suggest the following categories of $25(\mathrm{OH}) \mathrm{D}$ levels:

1) Severe deficiency (deficit): $<10 \mathrm{ng} / \mathrm{ml}$.

2) Moderate deficiency (deficit): 10-20 ng/ ml.

3) Insufficiency: 20-30 ng / ml.

4) Sufficiency: $>30 \mathrm{ng} / \mathrm{ml}$.

\subsection{Methods}

All studied pregnant women filled in a specially designed questionnaire, consisting of 50 questions concerning the course of the current pregnancy and pre-conception history (a structured questionnaire including demographic data, personal and family medical history, thyroid disorders, diabetes and chronic renal disease, past and current medication, vitamin D or other vitamin intake, etc.).

Morning blood sample was taken from the cubital vein and the levels of $25(\mathrm{OH}) \mathrm{D}$ were determined using standard Electro Chemyluminescence Immuno Assay (Competition principle) in a central laboratory on the day of the sampling. The results were determined via a calibration curve in $\mathrm{ng} / \mathrm{ml}$.

\subsection{Statistics}

The statistical analysis was performed using standard SPSS 13.0 for Windows: descriptive statistics (mean, median values, standard deviation), correlation and dispersion analysis (using parametrical and non-parametrical methods, including Student's t-test, Kruskal-Wallis test and Mann-Whitney test.), ANOVA testing, post-hoc test-Bonferroni. All values were presented as mean values with standard deviations, median or percentage (unless specified otherwise), $\mathrm{p}$ values below 0.05 were accepted as statistically significant.

\section{Results and Discussion}

For the whole group (547 pregnant women), the mean $25(\mathrm{OH}) \mathrm{D}$ level was $25.86 \pm 9.46 \mathrm{ng} / \mathrm{ml}$; median 24.51 (7.96-70.00), corresponding to mild insufficiency during the autumn. Table 1 presents the four groups according to vitamin D levels - severe deficiency, deficiency, insufficiency and sufficiency. 
Table 1. Vitamin D levels in the investigated cohort (n-547).

\begin{tabular}{lllll}
\hline & Category (group) & $\mathbf{2 5 ( O H ) D ~ l e v e l ~ ( n g / m l ) ~}$ & Number & \% \\
\hline 1 & Severe deficiency & $<10$ & 7 & 1.28 \\
2 & Deficiency & $10-20$ & 141 & 25.78 \\
3 & Insufficiency & $20-30$ & 251 & 45.88 \\
4 & Sufficiency & $\geq 30$ & 148 & 27.06 \\
\hline
\end{tabular}

Only $27.06 \%$ of the investigated pregnant women had sufficient levels of 25(OH)D above $30 \mathrm{ng} / \mathrm{ml}$ (group 4) and the other three groups (1, 2 and 3 ) had deficiency or insufficiency $-72.94 \%$. Table 2 demonstrates the prevalence of vitamin D severe deficiency, deficiency, insufficiency and sufficiency among the pregnant women who took and who did not take vitamin supplements.

Table 2. Prevalence of vitamin D status (severe deficiency, deficiency, insufficiency and sufficiency) at the background of vitamin intake and no vitamin intake among pregnant Bulgarian women.

\begin{tabular}{|c|c|c|c|c|}
\hline & \multirow{2}{*}{ Category } & \multirow{2}{*}{ Vitamin D level, ng/ml } & \multirow{2}{*}{$\begin{array}{l}\text { Vitamin intake, } \mathbf{n - 2 7 8} \\
\text { Number }(\%)\end{array}$} & \multirow{2}{*}{$\begin{array}{l}\text { No vitamin intake, n-269 } \\
\text { Number }(\%)\end{array}$} \\
\hline & & & & \\
\hline 1 & Severe deficiency & $<10$ & $4(1.44)$ & $3(1.12)$ \\
\hline 2 & Deficiency & $10-20$ & $57(20.5)^{* *}$ & $83(30.86)^{* *}$ \\
\hline 3 & Insufficiency & $20-30$ & $130(46.76)$ & $122(45.35)$ \\
\hline 4 & Sufficiency & $\geq 30$ & $87(31.29)^{*}$ & $61(22.68)^{*}$ \\
\hline
\end{tabular}

$* \mathrm{P}<0.05$ for the comparison between the groups with $25(\mathrm{OH}) \mathrm{D} \geq 30 \mathrm{ng} / \mathrm{ml} ; * * \mathrm{P}<0.01$ for the comparison between the groups with $25(\mathrm{OH}) \mathrm{D}<20 \mathrm{ng} / \mathrm{ml}$.

L. Mackillop suggests that when estimated pregnancy term is in winter (November-March) there is a high risk of developing vitamin D insufficiency and deficiency and should therefore be supplemented [15]. Therefore, we planned our screening programme in October - a suitable autumn month for the determination of vitamin D status in pregnant Bulgarian women before the beginning of the winter season.

We analyzed the drug intake (including prescription drugs, vitamins) during pregnancy and we found that only $278 / 547$ $(50.82 \%)$ were taking vitamins at the time of the investigation, as a monotherapy or in combination with other medications. In general, all combined drug supplements for pregnant women contain vitamin D in small quantities. Some pregnant women (about 20\%) have taken vitamin D supplementation only.

Table 2 demonstrates the vitamin supplement intake in pregnant women with severe vitamin D deficiency and vitamin D deficiency vs. women with sufficiency. The prevalence of vitamin D sufficiency showed significant difference between women who took and who did not take vitamin supplements $-31.29 \%$ vs $22.68 \%(\mathrm{P}<0.05)$, and in the prevalence of vitamin D deficiency $(<20 \mathrm{ng} / \mathrm{ml})-31.98 \%$ vs. $21.94 \%(\mathrm{P}<0.01)$. Therefore, if the pregnant woman should listen to the advice of the obstetrician / gynecologist to take vitamin supplementation, the chances of normal vitamin D levels are higher.

The comparative analysis of the two subgroups - taking and not taking vitamin supplements, revealed higher $25(\mathrm{OH}) \mathrm{D}$ levels in the first subgroup - $26.74 \pm 4.4 \mathrm{ng} / \mathrm{ml}$ vs. $24.95 \pm 4.9$ $\mathrm{ng} / \mathrm{ml}$, respectively $(\mathrm{P}<0.05)$, Figure 1 .

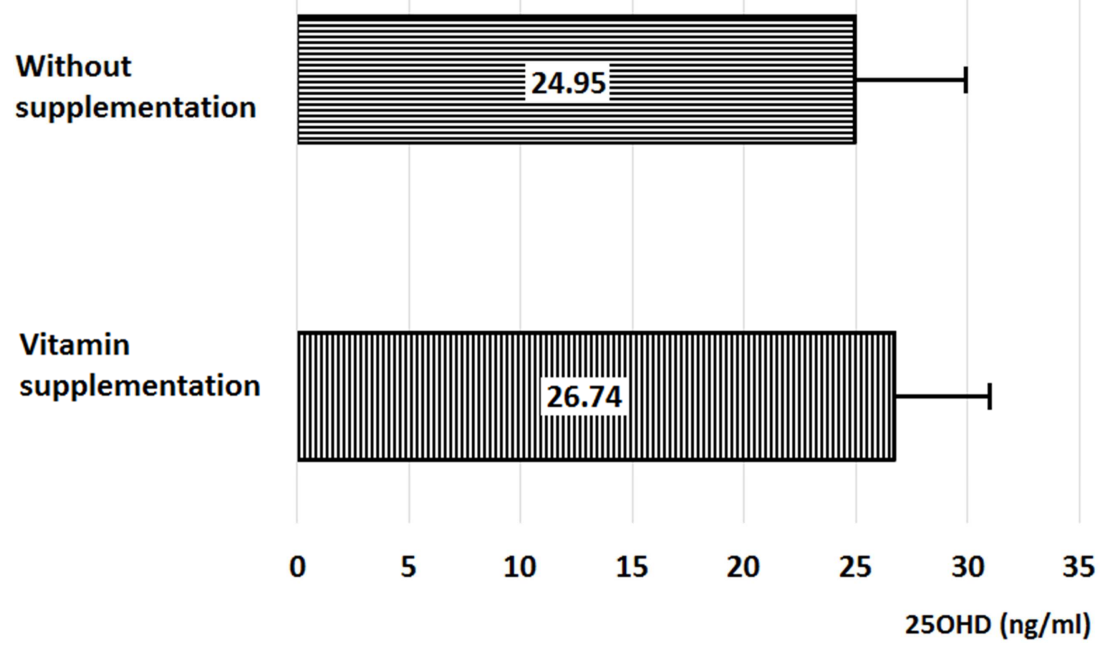

Figure 1. Mean levels of $25(\mathrm{OH}) D$ in pregnant women without vitamin supplementation and with vitamin supplementation. Results are presented as mean \pm SD. $P$ $<0.05$.

Table 1 demonstrates that nearly half of the studied pregnant women $45.88 \%$ have $25(\mathrm{OH}) \mathrm{D}$ insufficiency $(20-30 \mathrm{ng} / \mathrm{ml})$, $27.06 \%$ have sufficiency $(\geq 30 \mathrm{ng} / \mathrm{ml})$, and $27.06 \%$ - have deficiency or severe deficiency $(<20 \mathrm{ng} / \mathrm{ml})$. This distribution confirms the comparatively good vitamin D status of the studied pregnant Bulgarian women, probably due to the high proportion of women taking vitamin supplements.

It is difficult to compare our results with other European studies. For instance, in Slovenia ( $46^{\circ} \mathrm{N}$, i.e., more to the North) the corresponding studies were performed in March and June 
and do not allow direct comparison. The authors found a correlation between the intake of vitamin supplements and the levels of $25(\mathrm{OH}) \mathrm{D}$, and $23.6 \%$ of the studied pregnant women had severe vitamin D deficiency < $10 \mathrm{ng} / \mathrm{ml}$ [16]. Other authors also emphasize that it is important to consider the sampling season for vitamin D [1].

\section{Conclusion}

Vitamin D is important for musculoskeletal health, but there are data that vitamin D may be also important for fertility, pregnancy outcomes and lactation. Significant changes in vitamin D metabolism during pregnancy (increased production of calcitriol) support the important role of vitamin $\mathrm{D}$ in this period. The physiological vitamin D supplementation during pregnancy protect skeletal health [17].

The levels of vitamin D among pregnant Bulgarian women are within the span of mild insufficiency, probably due to the intake of vitamin D supplements by approximately half of the studied women during the pregnancy. In 50.82\% (278/547) of the pregnant women there is a combination of preparations containing vitamins and minerals taken alone or together with other medications, which is according to an approved protocol by Bulgarian obstetricians. Mother's more responsible behavior and concern for the fetus are the conditions for adherence to the advice of the gynecologist.

\section{Conflicts of Interests}

The authors declare that they have no competing interests.

\section{Acknowledgements}

The authors thank the endocrinologists and obstetrician/gynecologists who provided local support: V. Jotova (Troyan), S. Dimitrova (Gabrovo), Anchev (Gabrovo), Mitev (Gabrovo), A. Popov (Goce Delchev), A. Andreev (Samokov), E. Apostolova (Smolyan), M. Hubshev (Smolyan), S. Dimitrov (Pirdop), R. Naumovska (Pleven), M. Manuelyan (Burgas), K. Kirovakov (Burgas), Gabrovska (Burgas) M. Angelova (Stara Zagora), K. Venkova (Sofia), R. Velev (Sofia), I. Sigridov (Sofia), B. Bogoslovova (Sofia) ... total 104 specialists in the country. Technical support: T. Kornilova (Sofia), Z. Metodieva (Sofia), J. Georgieva (Sofia), H. Atanasova (Burgas), I. Ilieva (Stara Zagora).

This work was supported by grants from the Bulgarian Society of Endocrinology as part of the National Epidemiological Program for Pregnant Women in Bulgaria 2019.

\section{References}

[1] Danese E, Pucci M, Montagnana M, Lippi G. (2020). Vitamin D deficiency and pregnancy disorders. J Lab Precis Med; 5: 5 http://dx.doi.org/10.21037/jlpm.2019.11.03).

[2] Saraf R, Morton S. M, Camargo, C. A. Jr, Grant C. C. (2016). Global summary of maternal and newborn vitamin D status-A systematic review. Matern. Child Nutr. 12, 647-668.

[3] Kiely M. E, Wagner C. L, Roth D. E. (2020). Vitamin D in pregnancy: Where we are and where we should go. The Journal of Steroid Biochemistry and Molecular Biology. Volume 201, 105669 .

[4] Lambert PW, Stern PH, Avioli RC, Brackett NC, Turner RT, Greene A. (1982). Evidence for extrarenal production of 1a, 25-dihydroxyvitamin D in man. J Clin Invest. 69: 722-725. doi: 10.1172/JCI110501.

[5] Zehnder D, Bland R, Williams MC, McNinch RW, Howie AJ, Stewart PM, et al. (2001). Extrarenal expression of 25-hydroxyvitamin D3-1a-hydroxylase. J Clin Endocrinol Metab. 86: 888-894. doi: 10.1210/jc.86.2.888.

[6] Tamblyn JA, Hewison M, Wagner CL, Bulmer JN, Kilby MD. (2015). Immunological role of vitamin D at the maternal-fetal interface. J Endocrinol. 224: R114-117.

[7] Guideline: Vitamin D supplementation in pregnant women. Geneva: World Health Organization (2012). http://www.who.int/nutrition/publications/micronutrients/guid elines/vit_d_supp_pregnant_women/en/.

[8] Gallo S, McDermid JM, Al-Nimr RI, Hakeem R, Moreschi JM, Pari-Keener M, Stahnke, B, Papoutsakis C, Handu D, Cheng FW. (2020). Vitamin D Supplementation during Pregnancy: An Evidence Analysis Center Systematic Review and Meta-Analysis. J Acad Nutr Diet. May; 120 (5): 898-924.

[9] Brustad N, Garland J, Thorsen J, Sevelsted A, Krakauer M, Vinding RK, Stokholm J, Bønnelykke K, Bisgaard H, Chawes BL. (2020). Effect of High-Dose vs Standard-Dose Vitamin D Supplementation in Pregnancy on Bone Mineralization in Offspring Until Age 6 Years: A Prespecified Secondary Analysis of a Double-Blinded, Randomized Clinical Trial. JAMA Pediatr. Feb 24; 174 (5): 1-9.

[10] World Medical Association. Declaration of Helsinki: Ethical Principles for Medical Research Involving Human Subjects. JAMA. 2013; 310 (20): 2191-2194. doi: 10.1001/jama.2013.28105.

[11] Bischoff-Ferrari, HA (2012). Vitamin D-why does it matter? -defining vitamin D deficiency and its prevalence. Scand J Clin Lab Investig, 72 (Suppl 243): 3-6.

[12] Rosen, CJ., Abrams, SA., Aloia, JF., Brannon, PM., Clinton, SK., Durazo-Arvizu, RA., Gallagher, JC., Gallo, RL., Jones, G., Kovacs, CS., Manson, JE., Mayne, ST., Ross, AC., Shapses, SA., Taylor, CL. (2012). IOM committee members respond to Endocrine Society vitamin D guideline. J Clin Endocrinol Metab 97 (4): 1146-1152.

[13] Holick MF, Binkley NC, Bischoff-Ferrari HA, Gordon CM, Hanley DA, Heaney RP, Murad MH, Weaver CM. (2011). Evaluation, treatment, and prevention of vitamin D deficiency: an Endocrine Society clinical practice guideline. $J$ Clin Endocrinol Metab; 96 (7): 1911-1930.

[14] Dawson-Hughes, B. Vitamin D deficiency in adults: Definition, clinical manifestations and treatment. Up To Date Review 6 January 2017. Access date 13 February 2017. Available from: https://www.uptodate.com/contents/vitamin-ddeficiency-in-ad ults-definition-clinical-manifestations-and-treatment.

[15] Mackillop, M. (2019). Vitamin D Supplementation in Pregnancy. Oxford University Hospitals, NHS Foundation Trust. https://www.oxfordshireccg.nhs.uk/professional. 
[16] Dovnik, A., Mujezinovic, F., Treiber, M., Pecovnik, Balon B., Gorenjak, M., Maver, U., Takac, I. (2017). Determinants of maternal vitamin D concentrations in Slovenia. Wiener klinische Wochenschrift, vol. 129, 21-28.
[17] Pilz S, Zittermann A, Obeid R, Hahn A, Pludowski P, Trummer C, Lerchbaum E, Pérez-López F. R, Karras S. N, März W. (2018). The Role of Vitamin D in Fertility and during Pregnancy and Lactation: A Review of Clinical Data. Int. J. Environ. Res. Public Health 15, 2241. 